\title{
Mini-invasive treatment of sump syndrome: OverStitch choledochoduodenostomy revision
}

A 72-year-old woman, who was unfit for surgery, was admitted with recurrent cholangitis. She had a history of cholecystectomy and side-to-side choledochoduodenostomy (CDD) for huge impacted stones. In the previous year, she had undergone multiple endoscopic retrograde cholangiopancreatographies (ERCPs) with endoscopic sphincterotomy, incomplete stone extractions, and plastic stent placement in a local hospital. Magnetic resonance cholangiography showed multiple stones throughout the biliary tree, which was dilated up to $4 \mathrm{~cm}$, along with an incarcerated plastic stent.

Endoscopy with a frontal-view scope (GIF-1TH190; Olympus Europe) confirmed a 25-mm CDD in the duodenal bulb ( $\triangleright$ Fig. 1). Management of the huge impacted stones by conventional techniques was not feasible; therefore, a 1.9-Fr bipolar electrohydraulic lithotripsy probe (Autolith; Northgate Technologies Inc.) was passed through the working channel of the endoscope to break the stones under direct cholangioscopy guidance ( $>$ Fig.2). The scope channel allowed the removal of all fragments. Final fluoroscopy revealed a large diameter, atonic, empty biliary tree with delayed biliary outflow. A plastic stent was then inserted from the common bile duct to the duodenum, through the papilla, to promote drainage ( $>$ Fig. 3 ).

The patient returned 1 month later because of cholangitis. Endoscopy revealed a large amount of food debris in the biliary reservoir; a diagnosis of sump syndrome was made. Complete extraction of the food matter was performed. In order to prevent the recurrence of duodenocholedochal reflux, we decided to perform a stoma revision using the OverStitch device (Apollo Endosurgery; Austin, Texas, USA) to reduce the size of the CDD, leaving enough room for biliary outflow ( $\triangleright$ Video 1$)$. There were no post-procedural complications. The patient has

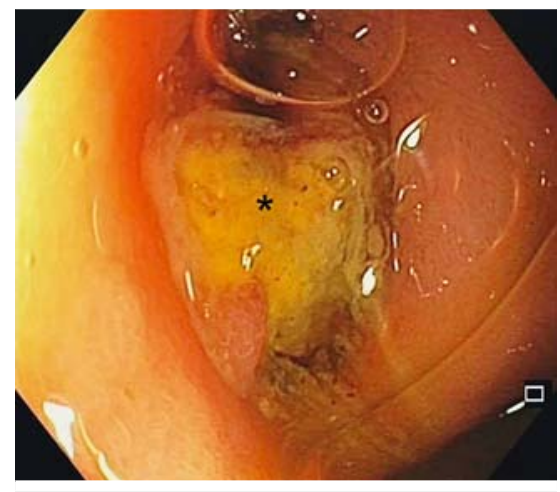

- Fig. 1 Endoscopic view showing a sideto-side choledochoduodenostomy with impacted stones (asterisk) that were causing biliary obstruction and acute cholangitis.

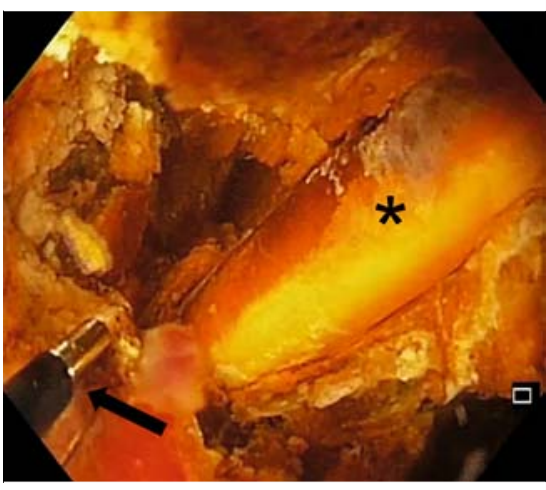

Fig. 2 Cholangioscopic view showing the electrohydraulic lithotripsy probe (arrow) located 1-2 mm from the surface of the gallstones, and ready to generate optimal fragmentation pressure under direct endoscopic control. In the common bile duct an incarcerated plastic stent is easily recognizable (asterisk).

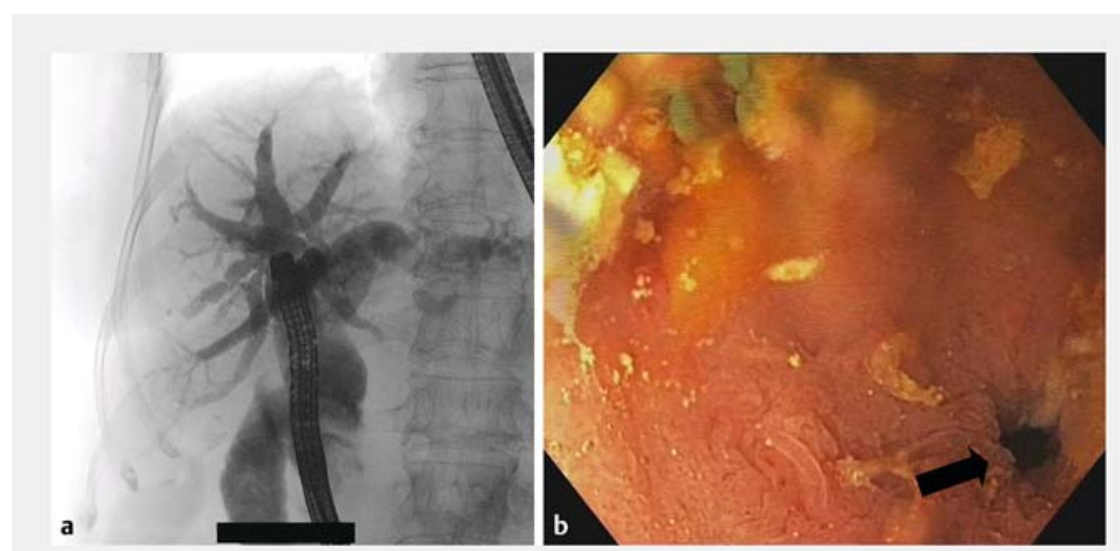

- Fig. 3 Images following the removal of stone fragments showing: a atony and marked dilation of the biliary tree (the endoscope is easily recognizable inside the intrabiliary ducts with direct access through the choledochoduodenostomy); $\mathbf{b}$ antegrade endoscopic placement of a biliary plastic stent from the common bile duct to the second part of the duodenum (major papilla area; asterisk).

remained asymptomatic during 1 year of follow-up (> Fig. 4).

Sump syndrome is a rare long-term complication of CDD, with a reported prevalence of $2.5 \%$ [1]. Endoscopic sphincterotomy is the treatment of choice but, if endoscopic treatment fails, surgery is advisable [2]. Evidence concerning endo- scopic closure of a CDD is lacking [3-5]. This is the first report detailing an endoscopic revision of a CDD using endoscopic suturing.

Endoscopy_UCTN_Code_TTT_1AR_2AG 


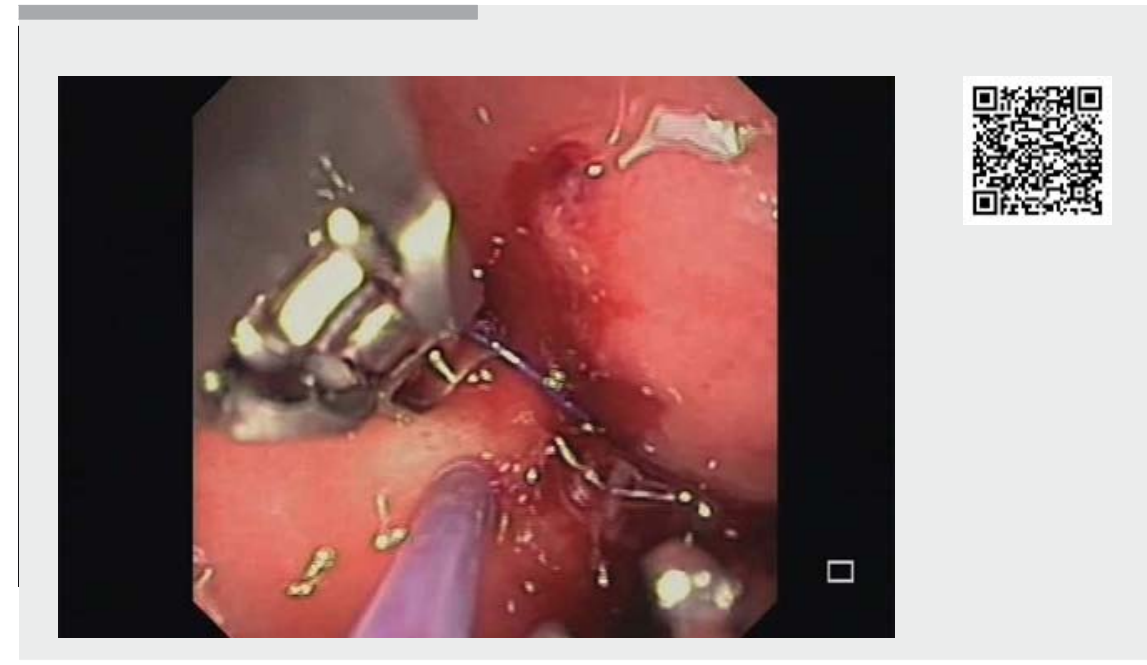

Video 1 Management of sump syndrome by electrohydraulic lithotripsy under direct cholangioscopy view and by choledochoduodenostomy revision using an endosuturing system

\section{Competing interests}

None

The authors

Antonino Granata ${ }^{1}$, Michele Amata ${ }^{1}$, Alberto Martino ${ }^{1}$, Dario Ligresti ${ }^{1}$, Sergio Li Petri ${ }^{2}$, Calogero Ricotta², Mario Traina ${ }^{1}$

1 Digestive Endoscopy Service, Department of Diagnostic and Therapeutic Services, IRCCSISMETT, Palermo, Italy

2 Abdominal Surgery and Organ Transplantation Unit, Department for the Treatment and Study of Abdominal Diseases and Abdominal Transplantation, IRCCSISMETT, Palermo, Italy

\section{Corresponding author}

\section{Antonino Granata, MD}

Endoscopy Service, IRCCS-ISMETT, Via

Tricomi 5, 90127 Palermo, Italy

Fax: +39-091-2192400 (specify Endoscopy

Service)

agranata@ismett.edu

\section{References}

[1] Leppard WM, Shary TM, Adams DB et al. Choledochoduodenostomy: is it really so bad? J Gastrointest Surg 2011; 15: 754 - 757

[2] Caroli-Bosc FX, Demarquay JF, Peten EP et al. Endoscopic management of sump syndrome after choledochoduodenostomy: retrospective analysis of 30 cases. Gastrointest Endosc 2000; 51: $180-183$

[3] Ell C, Boosfeld C, Henrich R et al. Endoscopic treatment of the "sump syndrome" after choledochoduodenostomy: a new technique using an amplatzer septal occluder. Z Gastroenterol 2006; 44: 1231-1235

[4] Ellison JC, Tarnasky PR. Endoscopic management of sump syndrome: closure of choledochoduodenostomy. Gastrointest Endosc 2014; 80: 725-726

[5] Ersoz G, Tekin F, Turan I et al. A novel method for closure of a choledochoduodenostomy in sump syndrome. Endoscopy 2015; 47 (Suppl. 01): E365-E366

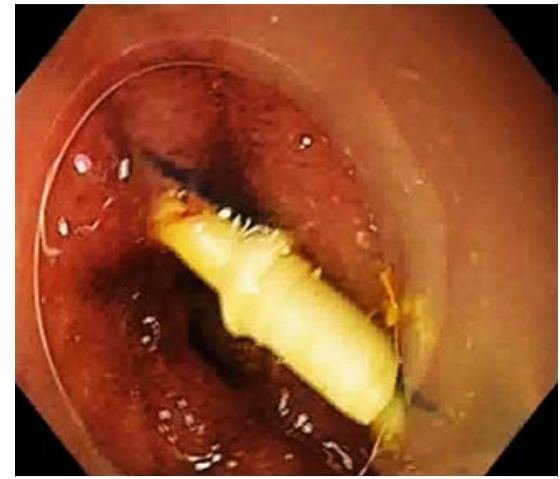

- Fig. 4 Follow-up endoscopic evaluation at 2 months showing a reduced caliber of the choledochoduodenostomy, with no evidence of lithiasis or food/debris inside.

\section{Bibliography}

DOI https://doi.org/10.1055/a-0919-4318

Published online: 4.6.2019

Endoscopy 2019; 51: E337-E338

(c) Georg Thieme Verlag KG

Stuttgart · New York

ISSN 0013-726X

\section{ENDOSCOPY E-VIDEOS \\ https://eref.thieme.de/e-videos}

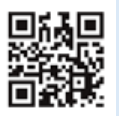

Endoscopy E-Videos is a free access online section, reporting on interesting cases and new

techniques in gastroenterological endoscopy. All papers include a high quality video and all contributions are freely accessible online.

This section has its own submission website at

https://mc.manuscriptcentral.com/e-videos 